\title{
Granule for Oral/Rectal Suspension Dosage Form
}

National Cancer Institute

\section{Source}

National Cancer Institute. Granule for Oral/Rectal Suspension Dosage Form. NCI

Thesaurus. Code C149550.

Solid preparation consisting of granules intended to be dispersed in the specified liquid to obtain an oral/rectal suspension. 